\title{
Determination of loratadine in pharmaceuticals by a spectrophotometric method
}

\author{
Georgeta PAVALACHE ${ }^{\mathrm{a}}$, Nicoleta MATEI ${ }^{* \mathrm{~b}}$ and Antoanela POPESCU ${ }^{\mathrm{a}}$ \\ ${ }^{a}$ Faculty of Pharmacy, OvidiusUniversity of Constanta, Constanta, Romania \\ ${ }^{b}$ Faculty of Applied Sciences and Engineering, Ovidius University of Constanta, Constanta, Romania
}

\begin{abstract}
The spectrophotometric method for determination of loratadine using tetraiodomercurate has been applied in various pharmaceutical formulations. The results confirmed that recovery value is optimum and the method is valid, thus it can be used in quality control and evaluation of loratadine tablets, oral formulations of mixed composition, oral solutions, etc. The method is easy and simple to apply, does not require complicated equipment and spectrophotometric reading time is reduced, which allows a large number of analyzes in a relatively short time.
\end{abstract}

Keywords: loratadine, UV-Vis spectrometry, potassium tetraiodomercurate, formulations.

\section{Introduction}

Loratadine (ethyl 4-(8-chloro-5, 6-dihydro-11Hbenzo $[5,6]$ cyclohepta $[1,2-b]$ pyridine-11ylidine)-1-piperidinecarboxylate) is a last generation of H1-antihistamine drugs used to treat allergies, marketed for its non-sedating properties [1,2]. At present, loratadine is quantified by spectrophotometry, high-performance liquid chromatography and electrospray mass spectrometry [3 - 5].

It was studied a spectrophotometric method for the determination of loratadine coupling with potassium tetraiodomercurate in an acid medium, the resulted compound showing an absorption maximum at $362 \mathrm{~nm}$, compared to loratadine in methanol which shows a maximum absorption at $288 \mathrm{~nm} \mathrm{[1,2,}$ $6,7]$.

Specific absorptivity coefficients of loratadine in methanol, solution respectively the reaction product are: $\mathrm{A}^{1 \%}{ }_{1 \mathrm{~cm}, 288 \mathrm{~nm}}=298$ and $\mathrm{A}^{1 \% \%}{ }_{1 \mathrm{~cm}, 362 \mathrm{~nm}}=1183$, so in this way the sensitivity of the determination of loratadine increased approximately 3 -fold.

Optimal parameters method were established $[8$, 9] as follows: detection wavelength $\lambda=362 \mathrm{~nm}$ at maximum absorbance, the optimum concentration of potassium tetraiodomercurate $2 \times 10^{-3} \mathrm{M}$, the reaction medium $(1 \mathrm{~mL} 0.05 \mathrm{M} \mathrm{HCl}$ was added to 5
$\mathrm{mL}$ sample), as well as stability of the samples (absorbance can be read after 10 minutes from the addition of the reagents, and the reaction product is stable for a further $10 \mathrm{~min}$ ) [6]. In the UV-Vis spectrum of loratadine in methanolic solution, the absorption band is shifted to higher wave number in the presence of tetraiodomercurate.

Established method for the determination of loratadine in the form of ionic association loratadine - $\left[\mathrm{HgI}_{4}\right]^{2-}$ was applied to in various pharmaceutical forms.

\section{Experimental}

Three pharmaceutical forms for internal use, namely: Tablets - Roletra, $10 \mathrm{mg}$ loratadine, producer: RANBAXY LABORATORIES LTD. INDIA; Modified-release tablets - Clarinase, 5 $\mathrm{mg} / 120 \mathrm{mg}$ loratadine/ pseudoephedrine sulphate, producer: SCHERING PLOUGH LABO N. V., BELGIA and Syrup - Symphoral, $1 \mathrm{mg} / \mathrm{mL}$, producer: GEDEON RICHTER SA ROMANIA, found on the Romanian market, were analyzed.

According to the prospectus, product Roletra 10 $\mathrm{mg}$ tablets contains $10 \mathrm{mg}$ loratadine and the following excipients: lactose monohydrate, maize starch, magnesium stearate, purified water.

The package insert Clarinase, modified-release tablets referred to the following composition: $5 \mathrm{mg}$ 
loratadine and $120 \mathrm{mg}$ pseudoephedrine sulfate, and the following ingredients: core - lactose monohydrate, maize starch, povidone, magnesium stearate; film coating - acacia, butyl parahydroxybenzoate, calcium sulfate dihydrate, carnauba wax, microcrystalline cellulose, oleic acid, gum arabic, flakes of soap, sucrose, talc, titanium dioxide, white beeswax, zein.

The product Symphoral syrup contains $1 \mathrm{mg} /$ $\mathrm{mL}$ loratadine and the following inactive ingredients: propylene glycol, glycerin, citric acid, sodium benzoate, disodium salt of ethylen diaminotetracetic acid (EDTA), artificial flavor, sugar and water.

For application of the method, the following materials were used: loratadine (CRS European Pharmacopoeia) [4], methanol (Merck), chloroform (Merck), 37\% hydrochloric acid (Tunic Prod. Bucharest), potassium iodide (Merck), mercury(II) chloride (Merck), double distilled water obtained with Millipore apparatus. The equipment used is UV-VIS spectrophotometer Jasco V-630 type series A040061148, program acquisition and data processing Spectra Manager, version 2, electronic analytical balance KERN \& SOHN ABJ 220-4M, WTW pH meter and 500 TurboVap Vaporizer.

Tablets samples were prepared as follows: it was determined the average weight $(0.1026 \mathrm{~g}$ for tablets and $0.9365 \mathrm{~g}$ for modified-release tablets) by weighing 20 tablets. The weighed tablets were brought into a mortar and were triturated to obtain a fine, homogeneous powder. A quantity of powder equivalent to 3-5 $\mathrm{mg}$ loratadine was weighed. The weighed powder and $20 \mathrm{~mL}$ of chloroform were brought into a $100 \mathrm{~mL}$ volumetric flask. For the extraction of loratadine in the formulation it was used chloroform whereas loratadine is readily soluble and excipients listed in the prospectus is sparingly soluble in mentioned solvent. The resulting suspension was filtered through quantitative filter paper and the filtrate was brought into vaporizer to completely remove the solvent. The residue was brought into $100 \mathrm{~mL}$ methanolic solution. Three samples were prepared for tablets (Table 1) and three samples for modified release tablets (Table 2) according to the procedure described above.
Table 1. Tablets sample preparation for applying spectrophotometric method.

\begin{tabular}{|c|c|c|c|}
\hline No. & $\begin{array}{c}\text { Weighed } \\
\text { quantity } \\
\text { of powder } \\
\text { from } \\
\text { tablets }(\mathrm{g})\end{array}$ & $\begin{array}{c}\text { Corresponding } \\
\text { amount } \\
\text { loratadine }(\mathrm{g})\end{array}$ & $\begin{array}{c}\text { Concentration } \\
\text { of the solution } \\
\text { in methanol } \\
(\mu \mathrm{g} / \mathrm{mL})\end{array}$ \\
\hline 1 & 0.0307 & 0.003 & 30 \\
\hline 2 & 0.0410 & 0.004 & 40 \\
\hline 3 & 0.0513 & 0.005 & 50 \\
\hline
\end{tabular}

Table 2. Modified-release tablets sample preparation for applying spectrophotometric method.

\begin{tabular}{|c|c|c|c|}
\hline No. & $\begin{array}{c}\text { Weighed } \\
\text { quantity } \\
\text { of powder } \\
\text { from } \\
\text { tablets }(\mathrm{g})\end{array}$ & $\begin{array}{c}\text { Corresponding } \\
\text { amount } \\
\text { loratadine }(\mathrm{g})\end{array}$ & $\begin{array}{c}\text { Concentration } \\
\text { of the solution } \\
\text { in methanol } \\
(\mu \mathrm{g} / \mathrm{mL})\end{array}$ \\
\hline 1 & 0.5619 & 0.003 & 30 \\
\hline 2 & 0.7492 & 0.004 & 40 \\
\hline 3 & 0.9365 & 0.005 & 50 \\
\hline
\end{tabular}

Syrup samples were prepared as follows: syrup volume corresponding to 5-7 $\mathrm{mg}$ loratadine and 10 $\mathrm{mL}$ of chloroform was brought into the extraction funnel. After vigorous stirring for 10 minutes, and the rest to the total separation of the two phases, chloroform component was collected in a flask with a stopper. The operation was repeated 4-5 times. Loratadine solution in chloroform was brought into the vaporizer for complete removal of solvent. The substance thus separated was processed similarly to that obtained from tablets and have prepared three such samples (Table 3).

Method. Nine samples were made from each formulation (three for each loratadine solution of each formulation) as follows: $1 \mathrm{~mL}$ of a solution of the loratadine formulation, $1 \mathrm{~mL}$ potassium tetraiodomercurate $2 \times 10^{-3} \mathrm{M}$ and $1 \mathrm{~mL}$ of $0.05 \mathrm{M}$ hydrochloric acid were brought in a measuring cylinder. It was completed to $5 \mathrm{~mL}$ with doubledistilled water. After 10 minutes, the absorbance was measured at a wavelength of $362 \mathrm{~nm}$ in $1 \mathrm{~cm}$ cuvette, against a blank prepared under the same conditions. 
Table 3. Syrup sample preparation for applying spectrophotometric method.

\begin{tabular}{|c|c|c|c|}
\hline No. & $\begin{array}{c}\text { The } \\
\text { volume } \\
\text { of syrup } \\
\text { taken } \\
\text { over } \\
(\mathrm{mL})\end{array}$ & $\begin{array}{c}\text { Corresponding } \\
\text { amount } \\
\text { loratadine }(\mathrm{g})\end{array}$ & $\begin{array}{c}\text { Concentration } \\
\text { of the solution } \\
\text { in methanol } \\
(\mu \mathrm{g} / \mathrm{mL})\end{array}$ \\
\hline 1 & 5 & 0.005 & 50 \\
\hline 2 & 6 & 0.006 & 60 \\
\hline 3 & 7 & 0.007 & 70 \\
\hline
\end{tabular}

The method was developed and validated. Calibration was performed on the concentration range of $10-100 \mu \mathrm{g} / \mathrm{mL}$, in our previous research $[6,7]$.

\section{Results and Discussions}

The concentration of Tablets Roletra analyzed samples was calculated using the equation of the calibration and the results presented in Fig. 1 were expressed in $\mu \mathrm{g} / \mathrm{mL}$ and as a percentage of the theoretical concentration.

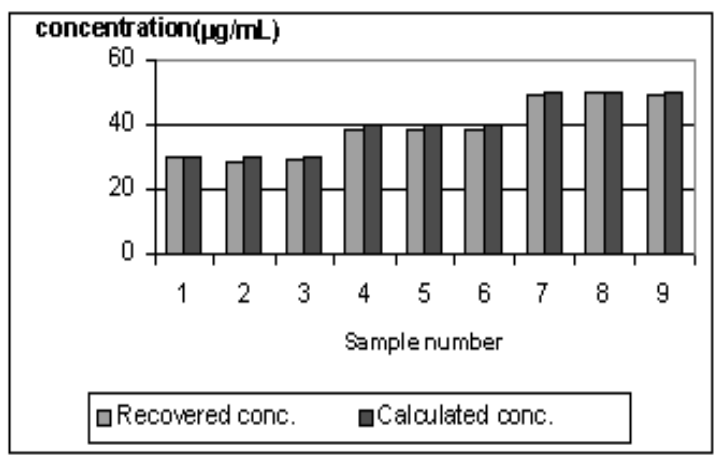

Figure 1. The variation of the calculated concentration to the concentration found in the analysis of loratadine tablets.

For the determination of loratadine in Tablets Roletra, recovering average is 97.908 with confidence interval $\mu=97.908 \pm 3.38$ (Table 4). The presented results confirmed that recovery conforms and the method is valid and can be used in quality control and evaluation of loratadine tablets.

It is noted that the two concentration values (concentration recovered and calculated concentration) are very close so the method is effective for this type of samples (Fig. 1).

Table 4. Statistical data.

\begin{tabular}{|c|c|}
\hline Average & 97.90863 \\
\hline Minimum & 96.31579 \\
\hline Maximum & 100.0789 \\
\hline Standard deviation (SD) & 1.464 \\
\hline $\begin{array}{c}\text { Relative standard deviation } \\
\text { (RSD) (\%) }\end{array}$ & 0.488 \\
\hline Degrees of freedom & 8 \\
\hline Error Probability 5\% & 0.05 \\
\hline t student value [10] & 2.31 \\
\hline Confidence Interval & $97.908 \pm 3.38$ \\
\hline
\end{tabular}

The concentration of the Tablets Clarinase samples was calculated using equation of the calibration and the results presented in Fig. 2 were expressed in $\mu \mathrm{g} / \mathrm{mL}$ and as a percentage of the theoretical concentration.

Recovered concentration values overlap with calculated concentrations, so the method proved to be reliable in Clarinase tablets that contain two active ingredients and a significant number of excipients (Fig. 2).

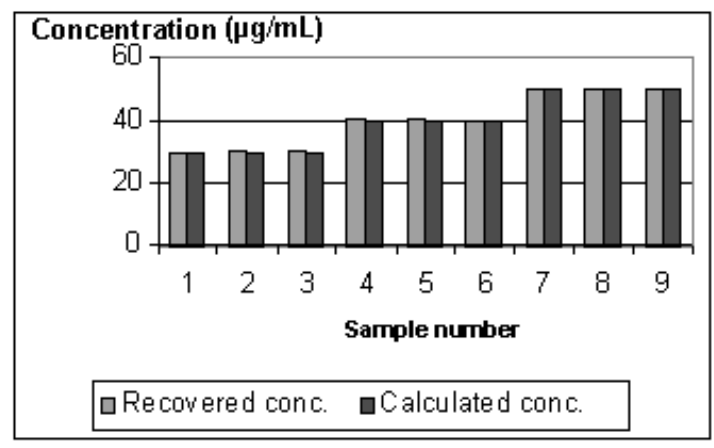

Figure 2. The variation of the calculated concentration to the concentration found in the analysis of Clarinase tablets.

For the determination of loratadine in Clarinase Tablets, recovery is 100.7122 mean with confidence interval $\mu=100.7122 \pm 2.57$ (Table 5). The presented results confirmed that recovery is optimal and the method is valid and can be used in quality control and loratadine dosage of oral formulations with mixed composition. 
Table 5. Statistical data

\begin{tabular}{|c|c|}
\hline Average & 100.7122 \\
\hline Minimum & 99.17763 \\
\hline Maximum & 102.3684 \\
\hline Standard deviation (SD) & 1.115609 \\
\hline $\begin{array}{c}\text { Relative standard deviation } \\
\text { (RSD) (\%) }\end{array}$ & 0.372 \\
\hline Degrees of freedom & 8 \\
\hline Error Probability 5\% & 0.05 \\
\hline t student value [10] & 2.31 \\
\hline Confidence Interval & $100.7122 \pm$ \\
& 2.57 \\
\hline
\end{tabular}

The concentration of Symphoral syrup samples was calculated using the equation of the calibration and the results presented in Fig. 3 were expressed in $\mu \mathrm{g} / \mathrm{mL}$ and as a percentage of the theoretical concentration.

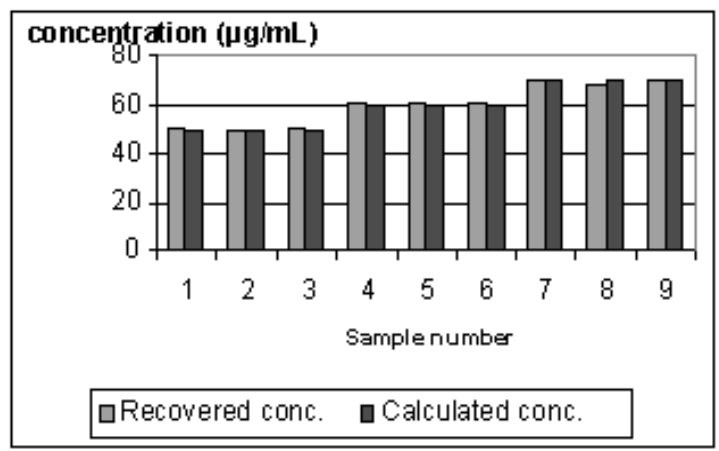

Figure 3. The variation of the calculated concentration to the concentration found in the analysis of Symphoral syrup

Table 6. Statistical data

\begin{tabular}{|c|c|}
\hline Average & 100.4817 \\
\hline Minimum & 98.15789 \\
\hline Maximum & 101.7895 \\
\hline Standard deviation (SD) & 1.0282 \\
\hline $\begin{array}{c}\text { Relative standard deviation } \\
\text { (RSD) (\%) }\end{array}$ & 0.3427 \\
\hline Degrees of freedom & 8 \\
\hline Error Probability 5\% & 0.05 \\
\hline t student value [10] & 2.31 \\
\hline Confidence Interval & $100.48 \pm 2.37$ \\
\hline
\end{tabular}

The method is specific for the syrup as well because values of recovered concentrations and calculated concentrations are similar and other components of the pharmaceutical preparation does not change the results (Fig. 3).

Recovery average is 100.48 with confidence interval of $\mu=100.48 \pm 2.37$ (Table 6) for loratadine determination in Symphoral syrup, so the method is efficient and can be used in quality control and determination of loratadine in oral solution.

Compared to other spectrophotometric methods presented in the literature $[1,2,5]$, this method has proven to be fast, with low limits of detection and quantification, far below the admissibility limit for the analysis and control of drugs.

\section{Conclusions}

The test method is suitable for the intended purpose, namely for determining low concentrations of loratadine in drug control tests for various pharmaceutical preparations.

For the determination of loratadine in all three formulations analyzed, it was obtained a mean recovery and a confidence interval corresponding norms. The method is easy and simple to apply on different formulations since no interference of excipients occurs.

\section{References}

* E-mail address: nmatei1977@yahoo.com

[1]. M.A. Abounassif, H.A. El-Obeid and E.A. Gadkariem, Journal of Pharmaceutical and Biomedical Analysis 36, 1011 (2005).

[2]. H. Mahgoub, A. A. Gazy, F. A. El-Yazbi, M. A. El-Sayed and R. M. Youssef, Journal of Pharmaceutical and Biomedical Analysis 31, 801, (2003)

[3]. A.N. Cristea, Farmacologie (in Romanian, Farmacology), Ed. Medicala, Bucuresti, 2000

[4]. *** European Pharmacopoeia 6.0, 2286 2288, 2007.

[5]. R.V.S. Nirogi, V.N. Kandikere, M. Shukla, K. Mudigonda, S. Maurya, R. Boosi and A. Yerramilli, Journal of Pharmaceutical and Biomedical Analysis 41, 935 (2001).

[6]. G. Pavalache, V. Dorneanu and A. Popescu, Ovidius University Annals of Chemistry 21, 83 (2010). 
[7]. G. Pavalache, V. Dorneanu and A. Popescu, Ovidius University Annals of Chemistry 21, 157 (2010).

[8]. J.M. Green, A practical guide to analytical method validation, Anal. Chem. News \& Features, 305A/309A, 1996.

[9]. R. Oprean, E. Rozet et al., Ghid de validare a procedurilor analitice cantitative (in Romanian, Validation guide of quantitative analytical procedures), Ed. Medicala Universitara „Iuliu Hatieganu” Cluj Napoca 2007.
[10]. L. Roman, M. Bojita and R. Sandulescu, Validarea metodelor de analiza si control (in Romanian, The validation of the analysis and control methods) Ed. Medicala, Bucuresti 1998.

[11]. ***Farmacopeea Romana, Ed. X, 1124-1162, 1998.

Received: 19 April 2015

Received in revised form: 25 May 2015

Accepted: 27 May 2015 